\title{
Operations Research in Healthcare: A survey
}

\author{
Abdur Rais $^{1}$, Ana Viana ${ }^{1}$
}

January 20, 2010

${ }^{1}$ INESC Porto, Campus da FEUP, Rua Dr. Roberto Frias 378, 4200-465 Porto, Portugal. email: \{arais,aviana\}@inescporto.pt

${ }^{2}$ ISEP - Instituto Superior de Engenharia do Porto

Rua Dr. António Bernardino de Almeida 341, 4200-072 Porto, Portugal 


\begin{abstract}
Optimisation problems in Healthcare received considerable attention for more than three decades. More recently, however, with decreasing birth rates in nearly all of the developed countries and increasing average longevity globally, optimisation issues in Healthcare have become noticeably important and attract keen interest from the Operations Research community. Over the years, attention has gradually expanded from resource allocation and strategic planning to include operational issues such as resource scheduling and treatment planning.

This paper surveys several applications of Operations Research in the domain of Healthcare. In particular, the paper reviews key contributions addressing contemporary optimisation issues in the area. It also highlights current research activities, focusing on the variety of optimisation problems as well as solution techniques used for solving the problems.
\end{abstract}

keywords: Healthcare, Operations Research, Optimisation, Survey 


\section{Introduction}

How to decide on the best locations of medical clinics and emergency vehicles for providing maximum Healthcare coverage to a given population? How many base locations of medical ambulances are needed if the total distance from the locations to the hospitals must be less than a given number? How should radiation treatment be planned for minimising treatment time of a cancer patient? How should the nurses in a trauma center be scheduled and re-rostered to maintain an adequate service level even in the worst-case scenario? Many problems like these need to be addressed in Healthcare and Operations Research (OR) provides numerous methodologies and solution techniques for tackling them.

Although optimisation problems in Healthcare received considerable attention over the last few decades, many issues are becoming much more important and relevant now because of the growth in aging population from decreasing birth rates in nearly all of the developed countries and increasing average longevity globally. Moreover, enormous public and private funds required to cover the rapidly-escalating Healthcare costs also necessitate much closer scrutiny for cost saving measures. For instance, the United States spends more than $\$ 2$ trillion or $16 \%$ of its GDP for Healthcare even though 50 million Americans do not have health insurance and another 25 million remain underinsured (Catlin et al. (2008)). Without a doubt, Healthcare is currently one of the main social and economic problems in the United States.

This paper surveys selected research work in OR applied exclusively to the problems in Healthcare. OR is getting utilised much more now to address dayto-day hospital management, resource-constrained operations or treatment planning aspects in Healthcare (Royston (2009)). Current research focus has led to the discovery of many new optimisation issues and development of many new solution approaches. Key healthcare optimisation issues include services planning, resource scheduling, logistics, medical therapeutics, disease diagnosis and preventive care. In particular, this survey addresses more recent and relevant works that have not been covered in other survey papers. It also provides the reader with information about seminal survey papers and books, was well as of research centres developing relevant work in this area.

The current section introduced the objectives of this paper. Planning aspects of healthcare are surveyed in Section 2. Works related to healthcare management and associated concerns are addressed in Section 3. Healthcare practice is addressed in Section 4, followed by Specialised and Preventive Care in Section 5. Section 6 concludes with some remarks. 


\section{Healthcare Planning}

Importance and significance of planning in healthcare can hardly be overemphasized today when providing for proper, adequate service continues to be a key concern of most countries. For growing longevity and ageing population amidst dwindling birth rates, many countries are increasingly hard-pressed for extra budget and resource to meet the healthcare needs. Many have turned to OR for optimisation and cost control measures. Some of the key healthcare issues considered in OR today include estimation of future demand for services in order to build enough capacity, selection of hospital locations for covering a target population, and design of the emergency facilities for efficient handling of the patients. A powerful tool for planning is Simulation (c.f. Jun et al. (1999), Fone et al. (2003), Ashton et al. (2005), Eldabi et al. (2007), Hall (2006), Gunal and Pidd (forthcoming), Gunal and Pidd (2009). But several other techniques have been successfully used, as shown in the following sections.

\subsection{Demand Forecasting}

Accurate demand forecasting is essential in healthcare planning, its results providing the input to several optimisation problems. While forecasting methods can be qualitative or quantitative, most research work has focused on quantitative analysis because of better accuracy. However, availability of good, historical data is essential for quantitative methods.

Finarelli Jr and Johnson (2004) gave a detailed, nine-step, quantitative demand forecasting model for healthcare services, while Cote and Tucker (2001) discussed four common methods for forecasting demand of healthcare services: percent adjustment, 12-month moving average, trendline and seasonality. Accuracies of various forecast methods was evaluated by Jones et al. (2008). They used data from daily patient arrivals at the emergency departments of three different hospitals and considered the following methods: time series regression, exponential smoothing, seasonal autoregressive integrated moving average, and artificial neural network models.

Beech (2001) derived market-based healthcare services forecasting from a broad range of available data for estimating the future demand. The data sets involve primary as well as secondary service areas, service-area populations by various demographic groupings, discharge utilisation rates, market size and market share by service lines. They found that market dynamics can allow a variety of explicit assumptions and trends for developing scenarios of potential future demand. 
A two-step approach for forecasting future demand along with capacity needs was given by Myers and Green (2004). In particular, their approach develops a facility master plan incorporating projected capacity as well as physician requirements.

Xue et al. (2001) analysed continued growth of the end-stage renal disease population in the US. They forecasted up to the year 2010 using historical data with stepwise autoregressive and exponential smoothing models.

\subsection{Location Selection}

A large body of publications in healthcare addressed various issues concerning capacity management and location selection, both for healthcare services and medical material (see, e.g. Ndiaye and Alfares (2008), Araz et al. (2007), Bruni et al. (2006), Rauner and Bajmoczy (2003), Verter and Lapierre (2003)).

Daskin and Dean (2004) reviewed location set covering, maximal covering, and P-median models for addressing the location planning issues in healthcare. They presented a novel application of the set covering model for analysing cytological samples. Additional review of location models in healthcare can be found in Smith-Daniels et al. (1988a). Review of location and allocation models restricted to developing countries can be found in Rahman and Smith (2000).

\subsubsection{Healthcare Centres}

Where to set healthcare centres for maximising accessibility has been extensively studied by OR practioners.

Location problems arising in developing countries were discussed by several authors. Smith et al. (2009) studied planning of sustainable community healthcare in the rural areas of the developing countries. They considered both top-down and bottom-up hierarchical location models for the efficient planning of community health schemes and proposed a Mixed Integer Program for determining the locations of maximal number of sustainable facilities.

Murawski and Church (2009) consider the problem of improving health service accessibility by upgrading links to existing facility locations of the transport network to all-weather roads. Their integer-programming model is adequate for rural areas of the under-developed countries where, during bad weather conditions, accessibility is diminished for lack of all-weather roads. Their model addressed a real-world problem scenario in Ghana.

A slightly different problem is solved in Ndiaye and Alfares (2008). They study the problem of selecting public service locations for nomadic population 
groups that seasonally change their locations. The authors have presented a binary integer-programming model to determine the optimal number along with the locations of the primary healthcare units that can satisfy seasonally-varying demands.

Rahman and Smith (1999) addressed the problem of finding additional suitable sites for healthcare facilities in rural areas and modelled the problem as a maximal covering location model. They solved the model using heuristic methods and data from Bangladesh.

Finally, Hodgson et al. (1998) used the covering tour model to plan mobile health services such that a sufficient number of facilities are geographically accessible as well as sustainable. Their integer linear-programming model minimises mobile facilities travel for serving all the population centres within a certain feasible range. They used exact as well as heuristic methods to solve the model and gave computational results using data from Ghana.

Additional location selection problems are discussed in Aaby et al. (2006a). This work presented a simulation tool for planning the locations of mass vaccination clinics in case of an influenza pandemic. Preventive healthcare facilities location is also studied by Verter and Lapierre (2003). They addressed this location problem so that participation in the prevention programs is maximised. They gave a mathematical-programming formulation and demonstrated the results using data from Georgia, USA, and Montreal, Canada.

Cote et al. (2007) addressed traumatic brain injury problems involving active duty military personnel. As timely treatment is critical for achieving recovery, being near a medical centre with specialised treatment services can be a critical factor. They developed a Mixed Integer Program for locating new treatment units while minimising the sum of patient costs (treatment, lodging, travel) along with the penalties associated for foregone treatment revenue and excess capacity utilisation.

The organisational structure of a transplant system in Italy, is the focus of the work by Bruni et al. (2006). They proposed a location model based on mathematical-programming for optimising such structure. In particular, they considered the critical role of time in the transplant process and the spatial distribution of the transplant centres. The objective of the model is to allocate transplantable organs across various regions with the strategic goal of achieving regional equity in healthcare.

Marianov and Taborga (2001) address location planning for public healthcare centres having the goal of maximising coverage for low-income population within a pre-specified distance and Harper et al. (2005) is concerned with ser- 
vice planning when the geographical locations of the services, as well as the patients needing services, are important altogether. A stochastic, geographical simulation model is developed to capture the underlying process of patients travelling to the providers while accounting for the necessary resource capacities, variability in patient needs, and travel considerations.

Joint capacity-planning and location-selection for determining locations and sizes of the medical departments in a hospital network is addressed by Stummer et al. (2004). They proposed a multiobjective decision-support system having mathematical-programming and real-world data from hospitals in Germany. Four objectives are considered: minimise total travel costs incurred by the patients; minimise total costs associated with location-allocation in the hospital plan; minimise the number of patients who would have to be rejected as a consequence of low service capacities (shortage of beds); and, minimise the number of unit moves necessary to restructure the current allocation.

Joint location-allocation is also addressed by Chu and Chu (2000) to study the planning issues of hospital location and service allocation for new service distribution as well as existing service redistribution. They developed a general modelling framework for supply and demand matching and solved their goalprogramming model using data in Hong Kong.

More recently, the work by Zhang et al. (2009b) addressed preventive healthcare facilities network design, regarding number of facilities and their location, with the aim of maximising the participation of the population in preventive healthcare programs.

Pierskalla and Brailer (1994); Pierskalla (2004) gave a comprehensive overview of blood banking supply chain and addressed various questions concerning blood banking functions and locations. In particular, they analysed how many community blood centres should be in a region and where they should be located; how supply and demand should be coordinated; and, how donor areas should be covered by community blood centres. They discussed tactical as well as operational issues confronting collection of blood, deciding on inventory levels, allocating blood to hospitals, and delivery to different sites.

\subsubsection{Emergency Vehicles}

Although in a smaller scale, location of emergency vehicles is also addressed in the literature, as follows.

A facility location model for ambulances that minimises the number of units needed for performing at pre-specified service levels was developed by Ingolfsson et al. (2008). They incorporated uncertainties and randomness into their convex 
optimisation model using actual data from Edmonton, Canada. They found the model to be tractable with general-purpose optimisation solvers for cities of up to one million population.

Araz et al. (2007) addressed the problem of determining the best base location of a limited number of emergency vehicles for optimising service levels. Three objectives measure the service levels: maximisation of the population covered by one vehicle; maximisation of the population with backup coverage; and, minimisation of the total travel distance from locations at a distance bigger than a pre-specified distance. They used a fuzzy, multiobjective model for solving the problem.

Henderson and Mason (2004) discussed a simulation and analysis software tool for ambulance service planning. The decision support tool has various advanced features for operations management at all levels (including strategic and tactical). It currently helps several organisations in Australia, New Zealand and the US for providing efficient ambulance services.

Finally, a trauma resource allocation model involving both hospitals and ambulances for maximising coverage for severely injured patients is discussed by Branas et al. (2000). They solved their integer-programming model by exact and heuristic methods using data from Maryland, USA.

\subsection{Capacity Planning}

Hospital capacity planning is full of challenging problems for OR practitioners. Green and Savin (2008), for example, used OR-based analyses to address the increasingly critical hospital capacity planning decisions. They used a queuing model formulation and gave examples of how OR models can be used for deriving important insights and operational strategies.

A cooperative solution approach for hospital capacity to treat emergency patients in Netherlands is proposed in Litvak et al. (2008). They presented a mathematical method inspired by the overflow model of phone calls in telecommunication and used simulation for validating the results. Emergency departments are also studied in Mayhew and Smith (2008). They used a queuing model to evaluate the emergency departments of the hospitals in UK. Per government mandated target, they focused on completing and discharging $98 \%$ of patients within four hours. Finally, Lovejoy and Li (2002) studied the problem of deciding whether the capacity of operating rooms in a hospital should be met by building new operating rooms or extending working hours in the current ones. They developed a multiobjective model with three objectives for addressing this issue: (1) minimise wait to get on schedule, (2) maximise schedule procedure 
start time reliability, and (3) maximise hospital profit. They focused on the trade-offs between objectives and validated the model using simulation.

At the tactical-level Adan et al. (2009) addressed the problem faced at a cardiothoracic surgery centre for optimising resource utilisation. They modelled it as a Mixed Integer Program having stochastic lengths of stay. Their results suggest that, for realising a given target of patient throughput, master surgical schedules with better performance on target utilisation levels of resources can be generated by considering a stochastic version of the deterministic problem.

Estimation of unavoidable hospital costs per unit of measurable output and identification of the sources of the inefficiencies is studied by Oliveira and Bevan (2008). They developed a stochastic multilevel model and applied it to hospitals in Portugal. Various inefficiencies arising from bed distributions, incentives and economies of scale were highlighted. The model could capture cost variations at different kinds of hospitals.

Discrete event simulation was used by Van Berkel and Blake (2007) to analyse the waiting lists for surgery in Nova Scotia, Canada. They developed a model for capacity planning decisions and analysed performance measures for enhancement as well as embellishment.

Chapter 2 of Brandeau et al. (2004) is entirely devoted to capacity planning and management in hospitals. Considerable amount of work has also been done on bed capacity planning (see Smith-Daniels et al. (1988b), Kokangul (2008), Harper and Shahani (2002) and Ridge et al. (1998)).

\section{Healthcare Management and Logistics}

Patient scheduling, resource scheduling, and logistics in healthcare are likely the most extensively referenced management problems in traditional OR journals. In particular, nurse scheduling has deserved special attention (see Burke et al. (2004) and Cheang et al. (2003)).

\subsection{Patient Scheduling}

An optimised patient-staff/patient-facilities schedule can lead to considerable cost reduction and increase in service quality.

The problem of scheduling patients for surgery at a hospital in Sweden given certain medical, economic and time constraints is addressed by Persson and Persson (2009). To prevent long queues, patients are allowed to be scheduled for surgery at other hospitals according to Swedish health policy. They developed a hybrid simulation and integer-programming approach for solving the problem. 
Patient-staff scheduling is studied in Ogulata et al. (2008). They developed hierarchical mathematical models to generate the schedules and considered three sub-problems: (1) selection of patients; (2) assignment of patients to the staff; and, (3) scheduling of the patients throughout the day. The objectives are to maximise the number of selected patients, to balance the workloads of physiotherapists, and to minimise waiting times of the patients on their treatment days. They tested their models with real-world data from hospitals.

Dynamic generation of patient schedules, having varying priorities, to public health-care facilities are modelled by Patrick et al. (2008) as a Markov decision process. The model is solved using Approximate Dynamic Programming and quality of solutions is analysed through simulation. Simulation is also used in Patrick and Puterman (2007) to improve resource utilisation for diagnostic services through exible inpatient scheduling.

Green and Savin (2008) addressed last-minute cancellations of patient appointments and modelled the problem as a single-server queue. They derived stationary distribution of the queue size and gave extensive computational results as well as guidance for relevant future work.

In another line, Jiang and Giachetti (2008) addressed patient flow in outpatient facilities and considered parallel activities for reduction of the cycle times. They improved on existing multi-class, open queuing, network models and demonstrated that parallelisation can indeed reduce the cycle times for the patients needing multiple diagnostic or treatment procedures. They compared the results with those obtained through simulation. Kaandorp and Koole (2007) considered outpatient appointment scheduling and derived a local search procedure that converges to the optimal schedule when the objective is a weighted average of expected waiting times of patients, idle time of the doctor, and tardiness (lateness). They found that, for a certain combination of the parameters, the Bailey-Welch rule gives optimal appointment schedule. A review on outpatient scheduling is provided by Cayirli and Veral (2003).

Genetic Algorithms were used by Chien et al. (2008) for scheduling patients and increasing service quality through reduction of patient waiting times and increase of therapy equipment utilisation. The problem is modelled as hybrid shop scheduling. A Mixed Integer Program is used as benchmark for validating solution quality. Empirical data from a medical centre in Taiwan is used to validate the approach.

Rauner et al. (2008) developed an internet game, based on discrete event simulation, to illustrate the economic and organisational decision-making processes in the hospitals. Managements from up to six hospitals can play for the 
patients of various disease categories and budgets; players can assess options for capacity planning and patient scheduling through analysis of resources, processes and financial results.

In Goddard and Tavakoli (2008) a queuing model to evaluate patient welfare under different systems is used to manage the waiting lists for public health services. They analyse various rules applied to the queueing model and discussed patient welfare as well as service efficiency aspects.

Queuing models are also used by Shmueli et al. (2003). They are based on the probability distribution of the number of occupied beds and aim at optimising admission to intensive care unit. They validated the model using data from a hospital in Israel with the objective of maximising the expected incremental number of lives saved by operating at the unit.

Challenges and research opportunities for appointment scheduling are discussed in Gupta and Denton (2008).

\subsection{Resource Scheduling}

Resource scheduling has been an active area of research in healthcare for increasing capacity utilisation, cost control measures, and improving tactical as well as operational efficiencies of services and facilities. Special attention has been given to nurse scheduling but several other issues have also been addressed.

\subsubsection{Nurse Scheduling}

In general, the nurse scheduling problem is that of assigning shifts to nurses having different skills while satisfying as many soft constraints and personal preferences as possible. Nurse schedule will typically strive to meet the required personnel coverage over a predefined planning period. Recent publications on nurse scheduling include Burke et al. (2008, 2006); Bard and Purnomo (2005b).

In a recent paper, Grano et al. (2008) developed a two-stage approach for nurse scheduling that considers both nurse preferences and hospital requirements. An optimisation model first awards shifts to the nurses with highest bids while satisfying all hospital constraints; subsequent optimisation then allocates the remaining shifts to all the nurses for completing the schedule. They applied the approach to a case study involving the emergency department of a hospital in Pennsylvania, USA. The problem is also addressed in Burke et al. (2006) that gave a real-world nurse-rostering methodology that is more flexible compared to the traditional fixed period-based approach. Burke et al. (2008) combined heuristic ordering with Variable Neighbourhood Search and Sundaramoorthi 
et al. (2008) developed a simulation approach to evaluate nurse-patient assignments. They used real data sets from a hospital in Texas to demonstrate their results.

In certain situations, patients may need to be assigned to specific nurses having special skills. Punnakitikashem et al. (2008) gave a stochastic programming approach for such nurse-to-patient assignments and Mullinax and Lawley (2002) gave mathematical programming and heuristic approaches for assigning nurses to critically-ill newborn infants.

A problem deserving special attention is the nurse rerostering problem. It arises when at least one nurse announces that she will be unable to undertake the tasks previously assigned to her. Pato and Moz (2008) solved this problem using a Genetic Algorithm while Moz and Pato (2005) tackled it as a bi-objective problem and solved using Goal Programming.

The problem of minimising the number of nurses that visit a patient (also known as "nurse-patient loyalty") is addressed by Steeg and Schroder (2007). For solution approach, they proposed a hybrid method combining Constraint Programming with large neighbourhood search metaheuristic. Along a similar line of research, Bertels and Fahle (2006) considered the problem of home healthcare and nursering; i.e., visiting and nursing patients in their homes. Besides finding the nurse schedules, the associated routing problem is also considered: Each nurse must be able to visit patients in a given roster using public transport. The goal is to minimise transportation costs and maximise satisfaction of both patients and nurses. A combination of Linear Programming, Constraint Programming and Metaheuristics is used to solve the problem.

Bard and Purnomo (2005b) addressed a nurse preference scheduling problem having both hard and soft constraints and solved using a combination of heuristic and integer-programming methods. They extended the work further in Bard and Purnomo (2005a) and improved the quality of schedules by incorporating a downgrading option. They also presented a model in Bard and Purnomo (2007) that combines cyclic as well as preference scheduling by formulating an Integer Program and decomposing it via Lagrangian relaxation.

The model presented in Felici and Gentile (2004) maximises staff satisfaction using a polyhedral approach. The authors described a particular sub-problem whose solution can be used to determine strong cuts for the complete problem and design branching rules to break the symmetries in the solution space. They demonstrated that these rules strongly impact the efficiency of the method.

Multiobjective personnel rostering is discussed in Berrada et al. (1996). The authors associated a slack variable to several soft constraints and considered 
objectives that minimise the slack values in a nurse scheduling problem. They used three different approaches for solving the problem: Sequential Technique, Equivalent Weights Technique, and Tabu Search. See Steuer (1985), Sherali (1982) and Glover and Laguna (2002), respectively, for details on the methodologies.

Other metaheuristic approaches can be found as follows: Evolutionary Algorithms in Aickelin et al. (2007), Aickelin and Dowsland (2004) and Aickelin and Dowsland (2000); Tabu Search in Bester et al. (2007), Ikegami and Niwa (2003), Dowsland and Thompson (2000) and Dowsland (1998); Scatter Search in Burke et al. (to be published) and Ant Colony Optimisation in Gutjahr and Rauner (2007). Bellanti et al. (2004) proposed both Tabu and Iterated Local Search procedures; Valouxis and Housos (2000) proposed Tabu and Local Search heuristics.

Some healthcare problems addressed personnel and facilities scheduling simultaneously; for instance, Belien and Demeulemeester (2008) integrated nurse scheduling with operating room scheduling and solved the problem using Linear Programming with Column Generation.

Personnel scheduling (mainly nurse scheduling or rostering) is extensively analysed in the survey papers by Ernst et al. (2004), Burke et al. (2004) and Cheang et al. (2003). Early research in nurse rostering is given in Pierskalla and Rath (1976) and Warner et al. (1990).

\subsubsection{Operating Room and Physician Scheduling}

Though of much interest, the problem of scheduling physicians and/or operating rooms in healthcare institutions has not received as much attention as nurse scheduling (c.f. Carter and Lapierre (2001)).

Operating room scheduling is discussed in Blake et al. (2002) and Blake and Donald (2002), among others. Their models can determine how much operating room time each surgeon should be assigned but, in most cases, cannot give detailed information on the timing of the assignments. Similarly, heuristics based on partial branch-and-bound are used in Beaulieu et al. (2000) for scheduling physicians in emergency rooms such that the sum of penalties associated with "deviation" constraints is minimised.

A different set of objectives is discussed in Ozkarahan (2000). They proposed a Goal Programming procedure for minimising idle time and overtime of operating rooms while simultaneoulsy maximising satisfactions of the surgeons, the patients and the staffs.

Lamiri et al. (2008) proposed a stochastic model for operating room planning 
with two types of demand for surgery: elective and emergency. Elective surgery can be planned ahead and have patient-related cost depending on surgery date. Emergency surgery arrives randomly and must be performed on the day of arrival. The planning problem consists of assigning elective cases to different periods over a planning horizon in order to minimise the sum of the elective patient-related costs and overtime costs of the operating rooms. They proposed a method combining Monte Carlo simulation with mixed Integer Programming.

An Integer Programming models is developed in Santibanez et al. (2007) to schedule surgical blocks for each specialty into Operating Rooms, considering Operating Rooms time availability and post-surgical resource constraints. The model was used by the hospitals in a British Columbia Health Authority. An Integer Programming model, together with Simulation, is also used in Zhang et al. (2009a) for allocating operating room capacity to specialties in a weekly basis. Minimization of inpatients' cost (measured by their length of stay) is expected.

A new approach for surgical case scheduling in hospitals through the extension of a Job Shop scheduling problem was developed by Pham and Klinkert (2008) while Green (2004) studied the problem of adjusting staffs in emergency rooms based on patient arrival rates so that timely care of the patients is optimised. He evaluated effectiveness of queueing models to identify the staffing patterns for reducing the fraction of patients who leave without being seen.

The problem of optimising the assignment of surgeries and sufficient planned slacks to the operating days such that the risk of working overtime is minimised, no surgeries are cancelled, and operating room utilisation is improved is addressed by Hans et al. (2008). They proposed several constructive and local search heuristics.

Resident on-call scheduling concerns work-nights of residents considering departmental staffing needs, skill requirements and resident preferences. The problem is solved in Wang et al. (2007) using Genetic Algorithms. In Sherali et al. (2002), the resident on-call scheduling problem is modelled as a Mixed Integer Program and solved by heuristic procedures that exploit the network structure embedded in the model.

Molema et al. (2007) analysed part-time work options for medical doctors. They illustrated through simulation of two case studies that introduction of part-time work can indeed improve service offerings and system design.

Concerns on bed occupancy are reflected in the work by Belien and Demeulemeester (2007). They addressed the problem of building surgery schedules with levelled resulting bed occupancy and considered two types of constraints: (1) 
demand constraints to ensure that each surgeon (or surgical group) obtains a specific number of operating room blocks, and (2) capacity constraints to limit the available blocks each day. Heuristics based on mixed Integer Programming and a metaheuristic are developed to minimise expected total bed shortage.

The schedule of emergency medical residents is constrained by a large number of rules: limits on number of consecutive work hours, number of day and night shifts that should be worked by each resident, resident staffing requirements according to seniority levels for the day and night shifts, restrictions on the number of consecutive day and night shifts assigned, vacation periods, weekend time-off requests, and fair distribution of responsibilities among the residents. Since some of these rules are conflicting, Topaloglu (2006) studied the problem from a multiobjective perspective.

Finally, Carter and Blake (2004) discussed four different problem instances in healthcare for which simulation can prove to be a good analysis tool: inpatient surgical scheduling; emergency room waiting time; emergency room scheduling; and, medicine ordering. They discussed obstacles as well as lessons learned from the simulation modelling techniques used.

Additional work on the scheduling of operating rooms can be found in Puente et al. (2009), Guinet and Chaabane (2003) and Dexter and Traub (1999). A review on operating room planning and scheduling is provided by Cardoen et al. (2010).

\subsection{Logistics}

Logistics in healthcare is concerned, among others, with the definition of medicine stock levels and allocation of resources.

Inventory needs are studied by Little and Coughlan (2008). They developed a constraint-programming optimisation model for the problem of inventory needs in hospitals constrained by importance associated with various product and service levels. Their model can determine optimal stock levels of products restricted by the space, delivery and criticality of the items. It was validated using sterile and bulk items in an intensive care unit of a hospital in Ireland.

Lapierre and Ruiz (2007) addressed hospital logistics by coordinating the procurement and distribution operations while respecting inventory capacities. Jacobson et al. (2006) calculated paediatric vaccine stockpile levels necessary for avoiding vaccination interruptions and Swaminathan (2003) proposed a multiobjective optimisation heuristic for allocating scarce drugs to clinics, having taken into account efficiency, effectiveness, and equity of the drug-allocation process. 
Rauner and Bajmoczy (2003) addressed the allocation of medical materials (semi-automated early defibrillators) to different regions of Austria. The problem considered acquisition and maintenance costs of defibrillators; training costs for emergency medical technicians; hospitalisation costs for patients with sudden cardiac arrests; future healthcare costs for surviving patients discharged from hospitals; and, improved survival as well as quality-of-life benefits from using the defibrillators. They developed a decision support system based on integer-programming models.

Van de Klundert et al. (2008) showed that up to $20 \%$ cost reduction is possible in Netherlands through optimisation of the flow of sterile instruments between sterilisation departments and hospital operating theatres along with streamlining of the processes and standardization of the materials. They showed the general instance of the problem to be NP-hard and gave an integer-programming formulation of a dynamic, non-deterministic model. They specifically addressed optimisation of the flow between the central sterilisation departments and the operating theatres by developing a cost minimisation model involving transportation and inventory. For this particular instance of the problem, they used Dynamic Programming to find a solution in polynomial time.

\subsection{Others}

Several researchers have looked into manufacturing and management areas of healthcare. This section discusses selected few.

Aktin and Ozdemir (2009) developed a two-stage approach for coronary stent manufacturing from one-dimensional cutting stock problem. The first stage calculates the number of patterns to be cut and the second stage finds the cutting plan. The problems were subject to demand, material availability, regular as well as overtime working hours, and due date constraints. They used two integer-programming models: One for solving the problem of minimising trim loss and the other for minimising total cost associated with material inputs, number of set-ups, labour hours and overdue time.

Haijema et al. (2007) discussed production and inventory management of platelets at a blood bank. They combined Markov Dynamic Programming with simulation and applied the approach to a real-world case of a Dutch blood bank.

Flessa (2003) developed a linear-programming model to analyse optimum allocation of budget to a set of healthcare resources (Prevention, Dispensaries, Health Centres, District Hospitals and Regional Hospital) in Tanzania. They addressed five different objectives: minimisation of death cases, minimisation of years of life lost, minimisation of incidence, minimisation of prevalence, and 
minimisation of loss of quality of life.

Kongnakorn and Sainfort (2004) reviewed health outcome modelling in general and detailed theoretical background for a Quality-Adjusted Life Years model grounded in OR and Utility Theory. They analysed various measures of health outcomes and gave comprehensive account of current issues and research directions.

Richter (2004) focused on clinical trials and discussed using the best currently available information for decision making in order to bridge the gap until better information becomes available. They showed that combination of OR and Health Economics has enormous potential for providing practical information to the decision makers.

Blood bank management policies, decisions and theories of perishable inventories are reviewed in Prastacos (1984) and Nahmias (1982). Although this seemed to be a promising area of research, OR/MS research in this area decreased considerably between mid-80s and 2004 as pointed out in Pierskalla (2004). Recently, Kopach et al. (2008) discussed management of red blood cell supplies based on two demand rates: urgent and non-urgent. They addressed the new supply needs and multi-tier control policies in view of extended expiration dates.

\section{Healthcare Practice}

Beside addressing various other healthcare management aspects, OR researchers have made significant contribution to drug treatment planning, infectious disease prevention and control, pandemic preparedness, emergency response, and organ donation.

\subsection{Disease Diagnosis}

The use of optimisation techniques for disease diagnosis is extensively discussed in Lee and $\mathrm{Wu}$ (2009). A review on the application of the Analytic Hierarchy Process to numerous problems in medical decision making is also provided in Liberatore and Nydick (2008). They summarised 50 different articles from seven categories: diagnosis, patient participation, therapy/treatment, organ transplantation, project and technology evaluation and selection, human resource planning, and healthcare evaluation and policy.

Abnormal brain activity is investigated in Chaovalitwongse et al. (2003). They applied global optimisation and dynamical systems for predicting epileptic seizures. Brain activity is also addressed by Chaovalitwongse et al. (2006) and 
Chaovalitwongse et al. (2008). The former applied optimisation-based data mining techniques to classify the brain's normal and epilepsy activities using intra-cranial electroencephalogram. The results of their studies suggest the possibility of design and development of efficient seizure warning algorithms for diagnostic and therapeutic purposes. The latter uses a new classification scheme for multidimensional time-series data. They used a mathematical-modelling framework for minimising errors in classification (or maximising the accuracy).

Cancer diagnoses are the focus of the work by Bortfeld et al. (2008) and Sofer et al. (2003). Bortfeld et al. (2008) addressed uncertainties in radiation therapy for cancer patients. They gave a robust-optimisation formulation of the problem that generalises mathematical-programming formulations. They also discussed extensive computational results using clinical data. Sofer et al. (2003) proposed an optimisation model to determine optimal biopsy protocols; i.e., the zones to be biopsied in order to maximise probability of cancer detection.

Paltiel et al. (2004) introduced "Asthma Policy Model" as a Markov statetransition simulation to forecast asthma-related symptoms, acute exacerbations, quality-adjusted life expectancy, healthcare costs, and cost-effectiveness. They gave extensive discussions of the results from simulation on 10-year horizon.

Finally, coronary risk prediction is addressed by Alexe et al. (2003). The authors introduced Logical Analysis of Data and discussed how it can be used for disease prediction.

\subsection{Treatment Planning}

Within Medical Therapeutics, an area that has been receiving special attention is radiation therapy (Preciado-Walters et al. (2006), Holder and Salter (2005)). Still, several other areas of planning and intervention have been subject of study as reflected in the papers by Paltiel et al. (2004), Lee et al. (2008) and Zenios (2004).

Recently, Holder (2004) gave a comprehensive discussion of linear- and nonlinear programming models for Intensity Modulated Radiotherapy Treatment (IMRT). In particular, they focused on the linear models in detail. Furthermore, Ehrgott et al. (2008) gave an extensive survey of the optimisation models, methods and theories concerning IMRT design.

IMRT, as well as three-dimensional conformal radiotherapy (3DCRT), are addressed in Ferris et al. (2004). The problems are described in quadratic, linear, piece-wise linear and non-linear formulations. The authors gave details on how to generate practical solutions and discussed several optimisation tools and programming environments. 
Minimisation of total treatment time in cancer radiotherapy using multileaf collimators is studied by Wake et al. (2009). The approach considers a Mixed Integer Program that happens to be a modification of a cutting-stock problem formulation. Maillart et al. (2008) developed a Markov chain model for investigating proper frequency of mammography screening. They analysed a broad range of screening policies and discussed computational results.

Kidney dialysis therapy initiation for evaluating cost and effectiveness is investigated in Lee et al. (2008). They used Approximate Dynamic Programming and Simulation to determine an optimal therapy and a strategy for maximising patient welfare.

Lee and Zaider (2004) described a clinical decision support system for treatment planning in Brachytherapy (placement of radioactive seeds inside a tumour) and used Mixed Integer Program for optimisation.

Davies and Brailsford (2004) described a simulation model for screening complications related to diabetes. In particular, they considered natural history of eye disease in patients with diabetes and discovered the trade-offs between screening frequency, screening sensitivity and patient compliance.

\section{$5 \quad$ Specialised and Preventive Healthcare}

Increase in longevity, escalating health-care costs and emergence of new diseases in recent years have forced medical decision-makers to focus strongly on preventive and specialised measures. Many researchers have used stochastic as well as discrete optimisation to analyse propagation of infectious diseases, evaluate cost-benefit aspects of the screening tests for susceptible groups in the population, and transplant as well as donation of vital organs. Terrorism as well as potential for bio-terrorism have added much more to the complexity and challenges of preventive care.

\subsection{Organ Donation and Transplant}

Most research work on organ transplantation focus on policies for allocating donated organs to the waiting patients (Bruni et al. (2006)), liver and specially kidney transplants being the most monitored problems.

Zenios (2002) addressed the mix of direct and indirect exchanges of organs that maximise the expected total discounted quality-adjusted life years of the candidates in the participating pairs. To capture the trade-off, they developed a double-ended queuing model for an exchange system with two types of donor-candidate pairs. They found direct exchanges to be preferable because 
the candidate receives a living-donor organ instead of an inferior cadaverous organ in indirect exchange. However, the latter involves a shorter waiting time. Zenios (2004) specifically addressed the problem of kidney transplantation and discussed the critical issues in vital organ transplant procedures. They analysed allocation, queuing and simulation models as the core OR methodologies for medical decision making. Su and Zenios (2006) presented the kidney allocation problem as a sequential stochastic assignment model with the objective of determining an organ allocation policy that maximises total expected reward. The stochastic model not only gives the patients a greater choice of their positions on the transplant waiting list, but also aims to create a more efficient and equitable system. Previously, Su and Zenios (2005) analysed kidney allocation considering society's as well as individual patient's perspectives. Zenios et al. (2000) also addressed a dynamic kidney allocation problem with three objectives: maximising the quality-adjusted life expectancy of transplant candidates; minimising a linear function of the likelihood of transplantation of the various types of patients; and, minimising a quadratic function that quantifies the differences in mean waiting times across patient types. They modelled with linear differential equations and approximate analysis of the optimal control problem in simulation using large dataset from transplants in the US. Six demographic groups based on sex, race and age groups were considered.

A software solution for optimising kidney pair donation based on maximum edge-weight matching algorithm is presented in Segev et al. (2005b). The algorithm first constructs a graph in which each node is an incompatible donorrecipient pair and each edge is a potential match between the two connecting nodes. The graph can be constructed by entering blood type, antibody, and antigen information for each pair of nodes. The matching algorithm then determines which pairs are compatible (possible matchings) and draws edges between the corresponding pairs. Finally, it compares all possible combinations of the matchings to determine the best possible solution for the given criteria. The software has already been used by many hospitals; detailed description can be found in Segev et al. (2005a).

Roth et al. (2004) addressed the problem of having a donor in a noncompatible patient-donor pair offering kidney to some other patient in the waiting list and Sandiki et al. (2008) addressed privacy concerns of the patients waiting for liver transplant and modelled the problem as a Markov decision process. They discussed conditions under which optimal solutions can exist. They also gave extensive details of the numerical studies conducted.

Liver transplants are analysed by Alagoz et al. (2004). They studied how to 
optimally time liver transplant to maximise the patient's total reward, namely quality-adjusted life expectancy. The problem is modelled as a Markov decision process in which the state is described by patient health. Later, Alagoz et al. (2007) suggests that much of the research work on optimal allocation of organs focused on designing an optimal allocation system for maximising society's welfare, such as: mean expected quality-adjusted life years and the average one-year graft survival probability. They addressed a decision problem faced by the patients with end-stage liver disease: whether to accept or decline an organ of a given quality. The problem is formulated as a Markov decision process in which the state is described by patient state and organ quality. Stahl et al. (2005) developed an integer-programming framework for determining configuration of the regions in US that maximise liver transplant allocation efficiency and geographic parity.

Shechter et al. (2005) designed a biologically-based discrete-event simulation to test changes in allocation policies for liver diseases. Another simulation model, that allows comparison of different policies for allocating donor hearts on pre-transplant outcomes, is presented in van den Hout et al. (2003).

Evaluation and comparison of different allocation methods for renal transplant in particular is given in Taranto et al. (2000). Hornberger and Ahn (1997), Ahn and Hornberger (1996) and David and Yechiali (1985) addressed the problem of deciding when to accept a cadaverous organ for maximising patient's benefit. A Game-theory based approach in which the players are the patientdonor pairs is given in Biro and Cechlarova (2007).

\subsection{Prevention of Diseases}

Optimisation problems related to prevention of diseases concern mostly vaccine selection.

The vaccine selection algorithm has been extensively studied since it was first introduced in Jacobson et al. (1999). Sewell and Jacobson (2003) extended the selection algorithm to cover the entire immunisation schedule. They developed an integer-programming model to assess the economic premium that exists in having combination vaccines available. The same authors in Jacobson and Sewell (2002) used Monte Carlo simulation in conjunction with reverse engineering to determine probability distributions of four hypothetical combination vaccines. They found that such information is useful for vaccine manufacturers to determine the fraction of the market share they may be able to attract for certain price ranges of the vaccine.

By incorporating the economic impact of wastage on the lowest overall cost 
formulary, Jacobson et al. (2004) modified the vaccine selection algorithm in Sewell and Jacobson (2003). Analysis is done for a set of vaccines, one vaccine at a time. Jacobson et al. (2003) reported on reverse engineering analysis of vaccine selection and detailed the economic value of Hepatitis B combination vaccine.

Hall et al. (2008) addressed a vaccine formulary problem for generic childhood immunisation schedules that minimises the weighted sum of the costs for immunising a child and the amount of extra-immunisation. The problem is shown to be NP-hard unless vaccines, schedule parameters, or the diseases are restricted. They formulated an integer-programming model to find the maximum number of vaccines that can be administered without extra-immunisation, which has been a major concern in the US for childhood immunisation programs. An exact Dynamic Programming algorithm along with a randomised heuristic for the integer-programming model is developed to solve the model. Computational effectiveness and limitations are discussed.

Finally, Wu et al. (2005) formulated the annual vaccine-strains selection problem as a stochastic dynamic program. They used the theory of shape space that maps each vaccine and epidemic strain to a point of a multidimensional space.

In another line, Earnshaw et al. (2007) addressed a resource allocation problem for HIV prevention and developed a linear-programming model for improving on past allocation strategies. Their results suggest that the model can serve as a tool for fund allocation in other prevention activities. Allocation of resources is also addressed in Harris (2006), Zaric and Brandeau (2001) and Zaric and Brandeau (2002). Harris (2006) used a non-linear optimisation model to determine resource allocation in a multiple-site needle exchange program to achieve the largest possible reduction in new HIV infections at minimum cost. Optimal allocation of HIV prevention funds among three types of prevention programs are analysed by Zaric and Brandeau (2001). They also investigated the impact of different allocation methods on health outcomes. Their goal is to maximise life years gained or HIV infections averted over a specified time horizon. The same authors, in Zaric and Brandeau (2002), developed a dynamic resource allocation model in which limited budget for epidemic control is allocated over multiple time periods. Brandeau et al. (2003) used non-linear optimisation techniques combined with epidemic modelling to determine the optimal allocation of limited resources for epidemic control in multiple, noninteracting populations. Brandeau (2004) extended the work to various related problems and gave a comprehensive overview of exact as well as non-exact OR 
techniques used for solving the problems.

Markov models are used in Sanders et al. (2005) and Harper and Shahani (2003) to deal with distinct problems. Sanders et al. (2005) used a Markov model of costs, quality of life, and survival associated with a HIV-screening program to analyse benefits and effectiveness of screening for HIV during the highly active antiretroviral therapy. Harper and Shahani (2003) developed a Markov operational model of patient care and used simulation to predict future patient numbers as well as associated healthcare costs at different AIDS clinics of India. Markov models are also used in Siebert et al. (2003) as a decisionanalytic tool for economic evaluation and cost-effectiveness of human papilloma virus testing in cervical cancer screening.

Contact tracing or partner notification can help to control infectious disease spread but determining the optimal level of investment required is challenging. Armbruster and Brandeau (2007) presented a simulation-based methodology to evaluate cost and effectiveness of different levels of contact tracing and extended the model to optimal budget allocation. They discussed how a simulation model can be used as a policy-making tool.

Influenza is the leitmotif for the work by Van Genugten et al. (2003). They considered influenza pandemic situations and used scenario analysis on potential effects of intervention options for making the policy decisions on design and planning of outbreak control management. Chick et al. (2008) studied supply chain issues related to influenza vaccination programs. They developed a variant of the cost-sharing contract that provides incentives for the supply chain to achieve global optimisation with improved supply of vaccines. Nigmatulina and Larson (2009) considered mitigation strategies for global pandemic influenza and used spreadsheet-based models to report on non-pharmaceutical intervention strategies. Infection spread between heterogeneous communities is studied using Monte Carlo simulations, having incorporated into the model a feedback parameter to represent the changes in human behaviour.

Kaplan and Wein (2004) discussed various aspects of bioterror preparedness and evaluated consequences of different attack scenarios paired with alternative preparedness and response policies. They used Smallpox in a case study and reviewed the US vaccination policy of 2002 in a decision analysis framework.

Aaby et al. (2006b) used discrete-event simulation, capacity-planning and queuing-system models for planning of emergency mass dispensing and vaccination clinics. The same methodology is used in Mark et al. (2002) for devising guidance for prevention of coronary heart disease.

Diabetes and Hepatitis are also addressed by some authors. Harper et al. 
(2003) discussed prevention and treatment of diabetic retinopathy. Earnshaw et al. (2002) designed a linear-programming model to select interventions for preventing complications of Type-2 diabetes and maximising quality-adjusted life years subject to budget and equity constraints. The interventions considered are intensive glycemic control, intensified hypertension control, cholesterol reduction, and smoking cessation. Singer and Younossi (2001) used Markov decision analysis models to estimate the cost effectiveness of screening for Hepatitis $\mathrm{C}$ in asymptomatic, average-risk adults and Stein et al. (2004) used sensitivity analyses in spreadsheet-based models to estimate cost utility of testing for Hepatitis $\mathrm{C}$ in the drug users in UK.

\section{Concluding Remarks}

Papageorgiou (1978) presented one of the earliest surveys of OR applied to problems in healthcare. They highlighted how design, operation and management of hospitals can be improved by OR. Since then, OR methodologies have been successfully applied to a variety of optimisation problems arising in healthcare.

During the last decade, OR research communities have become increasingly more interested to tackle numerous challenging problems in healthcare. By addressing the underlying optimisation issues, both deterministic and nondeterministic models have been used to capture the real-world needs and provide a systematic framework for analysis and evaluation. Many new problems have been solved and many previously-known "best" solutions as well as solution techniques have been improved. They helped significantly to improve the planning, delivery and management of healthcare.

Simulation and related non-deterministic research in OR covers around $15 \%$ of the recent publications in healthcare applications (see Brandeau et al. (2004) and Pardalos et al. (2004)). Researchers have addressed mostly the optimisation problems associated with hospital admission, hospital services, patient recovery, resource planning, facility utilisation, logistics, supply-chain coordination, vaccination, bioterrorism, and emergency response.

The majority of current publications in the deterministic side of OR involve mathematical-programming models and address a range of solution techniques including column-generation, shadow pricing, primal-dual, branch-andcut, branch-and-bound and interior-point methods. Dynamic programming models have been used for surgery and emergency room scheduling, vaccine formulary, as well as capacity planning. Key application areas include: treatment selection and radiotherapy treatment planning (Floudas and Pardalos 
(2009), Preciado-Walters et al. (2006), Ferris et al. (2003)); emergency-related resource/budget allocation, location planning for medical services, staff and shift scheduling (Oliveira and Bevan (2006), Shuman et al. (1975)); epidemic modelling (Kahn et al. (1998)).

Many problems in healthcare are quite understandably very complicated and cannot be captured using linear relationships. Quadratic Programming, Gradient Projection and Convex Programming have been used for radiotherapy planning (Fox et al. (2006), Ferris et al. (2003)). Non-linear Dynamics has been used for designing seizure warning algorithms (Pardalos et al. (2004)).

An interesting growing area of current research involves combining different OR methodologies for solving certain complex classes of problems in healthcare. Neural Networks has been used in a linear-programming model for optimising radiotherapy planning (Wu et al. (2000)). Simulated Annealing has also been used as a heuristic optimisation approach for radiotherapy planning (Webb (1991), Shu et al. (1998)).

Another area of research explores techniques that have been sucessfully used in other domains of application and analysis whether such techniques are also suitable in the healthcare domain. Naseer et al. (2009), for example, makes the parallellism with the defense sector. Practices and strategies successfully explored in the manufacturing sector (Lean Manufacturing, Six Sigma, Theory of Constraints) are addressed by, e.g. Young et al. (2004), Umble and Umble (2006) and Joosten et al. (2009).

Considerably less work seems to have been done with potentially promising methodologies such as scenario planning, robust optimisation and reliability modelling. In particular, adaptability and reliability aspects are important for healthcare delivery systems to perform well despite capacity limitations or facility closures (Daskin and Dean (2004)).

Tackling the wide range of optimisation problems in healthcare will certainly require considerable amount of research work. Identifying the optimisation issues and capturing the relevant parameters in mathematical models can be challenging. Finding appropriate solution techniques or formulating new methodologies for solving the models can be tricky. Although OR researchers have already dealt with many new problems and solution methodologies, much still remains to be investigated and solved in this enormous as well as complex problem domain. 


\section{Selected Relevant Information}

The large number of recent publications cited in this survey paper is certainly indicative of the importance of healthcare to OR professionals. Various ORrelated research centres, professional societies and networking groups are known to be actively engaged in healthcare issues. Selected relevant information, as well as information sources that can be important to the researchers but are typically not found in publications, are presented in this appendix. Several relevant seminal books and special issues of journals are also listed.

Table 1: OR in Healthcare: Research Centres

\begin{tabular}{|c|}
\hline \\
\hline $\begin{array}{l}\text { Medical Operations Research Laboratory (morLAB) } \\
\text { University of Toronto, Canada. }\end{array}$ \\
\hline $\begin{array}{l}\text { Center of excellence in Mathematical Sciences (MITACS) } \\
\text { University of British Columbia, Canada. }\end{array}$ \\
\hline $\begin{array}{l}\text { Center for O.R. in Medicine and HealthCare at GeorgiaTech } \\
\text { GeorgiaTech, USA. }\end{array}$ \\
\hline $\begin{array}{l}\text { Centre for Operational Research and Applied Statistics } \\
\text { University of Salford, UK. }\end{array}$ \\
\hline $\begin{array}{l}\text { Health Management Consortium } \\
\text { McGill University, Canada. }\end{array}$ \\
\hline $\begin{array}{l}\text { Operations Research Manhattan } \\
\text { Cornell University, USA. }\end{array}$ \\
\hline $\begin{array}{l}\text { Health Policy Institute } \\
\text { Boston University, USA. }\end{array}$ \\
\hline $\begin{array}{l}\text { Regenstrief Center for Healthcare Engineering } \\
\text { Purdue University, USA. }\end{array}$ \\
\hline $\begin{array}{l}\text { Centre for Research in Healthcare Engineering } \\
\text { University of Toronto, Canada. }\end{array}$ \\
\hline $\begin{array}{l}\text { Operations Research for Improved Cancer Care } \\
\text { University of British Columbia, Canada. }\end{array}$ \\
\hline $\begin{array}{l}\text { Center for Health Care Management } \\
\text { University of British Columbia, Canada. }\end{array}$ \\
\hline $\begin{array}{l}\text { Health Systems Research Center } \\
\text { University of Lancaster, UK. }\end{array}$ \\
\hline
\end{tabular}

Table 2: OR in Healthcare: working groups

\begin{tabular}{|l|}
\hline \multicolumn{1}{|c|}{ Working groups within OR associations } \\
\hline \hline INFORMS Health Applications Section \\
\hline EURO Working Group on OR in Computational Biology, Bioinformatics and Medicine \\
\hline EURO working group on OR applied to health services \\
\hline Health and Social Services. The OR Society of UK \\
\hline
\end{tabular}


Table 3: OR in Healthcare: Governmental entities Governmental entities

\begin{tabular}{|l|}
\hline Department of Health and Human Services, USA \\
\hline National Institute of Health, USA \\
\hline Office of Disease Prevention and Health Promotion, USA \\
\hline Agency for Healthcare Research and Quality, USA \\
\hline
\end{tabular}

Table 4: OR in Healthcare: Books Books

Operations Research in Health Care: A critical analysis.

Shuman et al. (1975)

Operational Research applied to health services.

Boldy (1981)

Modeling the AIDS epidemic: Pplanning, policy, and prediction.

Kaplan and Brandeau (1994)

No time to lose: Getting more from HIV prevention.

Ruiz et al. (2001)

Quantitative evaluation of HIV: Prevention programs.

Kaplan and Brookmeyer (2002)

Operations Research and Health Care. A handbook of methods and applications.

Brandeau et al. (2004)

Quantitative Neuroscience: Models, algorithms, diagnostics, and therapeutic applications.

Pardalos et al. (2004)

Patient flow: Reducing delay in healthcare delivery.

Hall (2006)

Optimization in Medicine.

Alves et al. (2008)

Optimization in Medicine and Biology.

Lim and Lee (2007) 
Table 5: OR in Healthcare: Journals' special issues

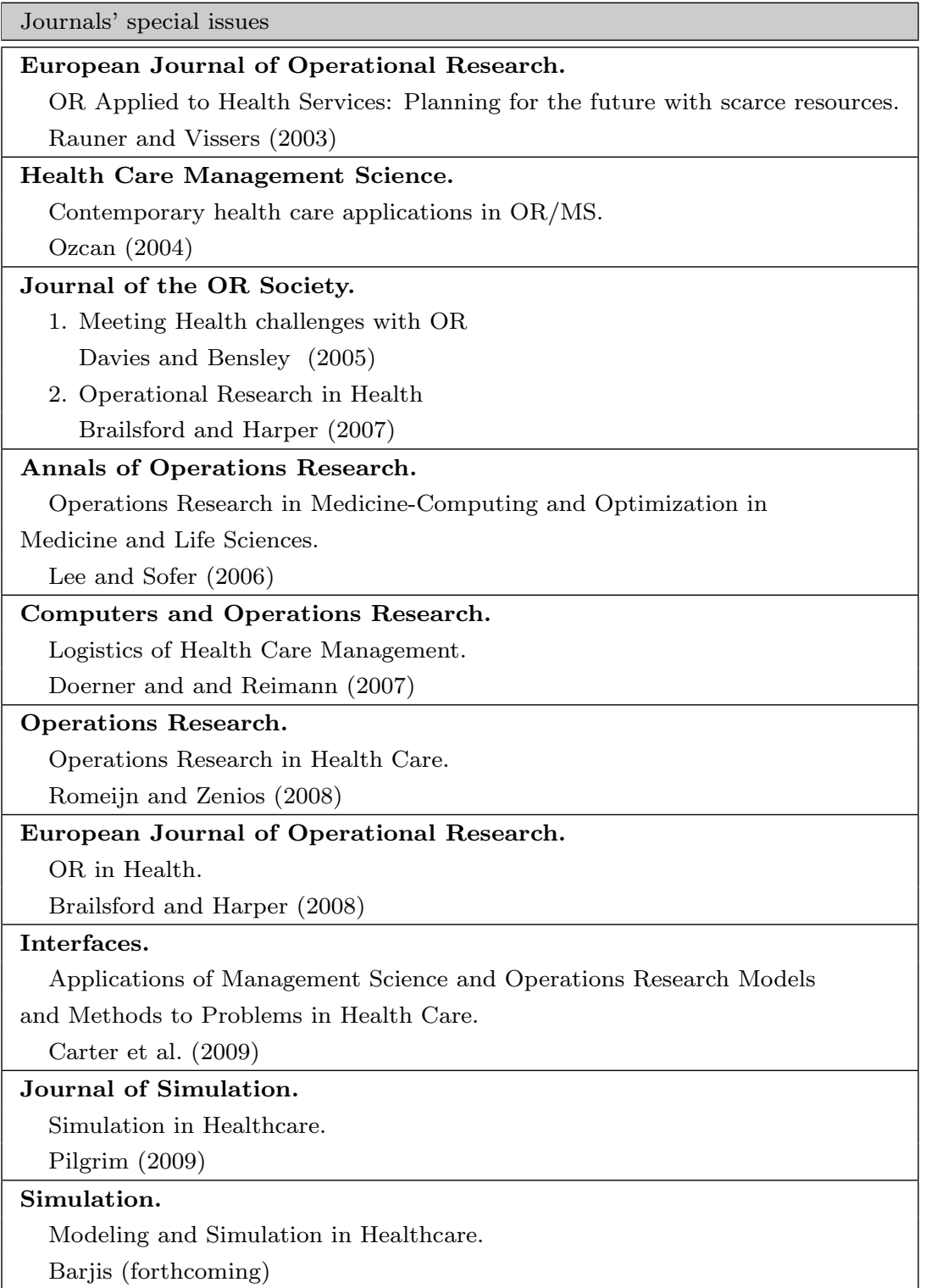




\section{References}

Aaby, K., Abbey, R. L., Herrmann, J. W., Treadwell, M., Jordan, C. S., and Wood, K. Embracing computer modeling to address pandemic influenza in the $21^{\text {st }}$ century. J. Public Health Management Practice, 12:365-372, 2006a.

Aaby, K., Herrmann, J. W., Jordan, C. S., Treadwell, M., and Wood, K. Montgomery county's public health service uses operations research to plan emergency mass dispensing and vaccination clinics. Interfaces, 36(6):569-579, 2006b.

Adan, I., Bekkers, J., Dellaert, N., Vissers, J., and Yu, X. Patient mix optimization and stochastic resource requirements: a case study in cardiothoracic surgery planning. Health Care Management Science, 12(2), 2009.

Agency for Healthcare Research and Quality, USA. Center for primary care, prevention and clinical partnerships and center for outcomes and evidence. http://www.ahrq.gov. (last visited on September 9, 2009).

Ahn, J.-H. and Hornberger, J. C. Involving patients in the cadaveric kidney transplant allocation process: a decision-theoretic perspective. Management Science, 42(5):629-641, 1996.

Aickelin, U., Burke, E. K., and Li, J. An estimation of distribution algorithm with intelligent local search for rule-based nurse rostering. Journal of the Operational Research Society, 58:1574-1585, 2007.

Aickelin, U. and Dowsland, K. Exploiting problem structure in a genetic algorithm approach to a nurse rostering problem. Journal of Scheduling, 3(3): 139-153, 2000.

Aickelin, U. and Dowsland, K. A. An indirect genetic algorithm for a nursescheduling problem. Computers \& Operations Research, 31(5):761-778, 2004.

Aktin, T. and Ozdemir, R. G. An integrated approach to the one-dimensional cutting stock problem in coronary stent manufacturing. European Journal of Operational Research, 196:737-743, 2009.

Alagoz, O., Maillart, L. M., Schaefer, A. J., and Roberts, M. S. The optimal timing of living-donor liver transplantation. Management Science, 50(10): 1420-1430, 2004.

Alagoz, O., Maillart, L. M., Schaefer, A. J., and Roberts, M. S. Determining the acceptance of cadaveric livers using an implicit model of the waiting list. Operations Research, 55(1):24-36, 2007. 
Alexe, S., Blackstone, E., Hammer, P., Ishwaran, H., Lauer, M., and Pothier Snader, C. Coronary risk prediction by logical analysis of data. Annals of Operations Research, 119(1-4):15-42, 2003.

Alves, C., Pardalos, P. M., and Vicente, L. N., editors. Optimization in Medicine, volume 12 of Springer Optimization and Its Applications. Springer, 2008.

Araz, C., Selim, H., and Ozkarahan, I. A fuzzy multi-objective covering-based vehicle location model for emergency services. Computers $\&$ Operations Research, 34(3), 2007.

Armbruster, B. and Brandeau, M. L. Contact tracing to control infectious disease: when enough is enough. Health Care Management Science, 10:341$355,2007$.

Ashton, R., Hague, L., Brandreth, M., Worthington, D., and Cropper, S. A simulation-based study of a nhs walk-in centre. Journal of the Operational Research Society, 56(2):153-161, 2005.

Bard, J. F. and Purnomo, H. W. A column generation-based approach to solve the preference scheduling problem for nurses with downgrading. SocioEconomic Planning Sciences, 39(3):193-213, 2005a.

Bard, J. F. and Purnomo, H. W. Preference scheduling for nurses using column generation. European Journal of Operational Research, 164(2):510-534, 2005b.

Bard, J. F. and Purnomo, H. W. Cyclic preference scheduling of nurses using a lagrangian-based heuristic. Journal of Scheduling, 10(1):5-23, 2007.

Beaulieu, H., Ferland, J., Gendron, B., and Michelon, P. A mathematical programming approach for scheduling physicians in the emergency room. Health Care Management Science, 3(3):193-200, 2000.

Beech, A. J. Market-based demand forecasting promotes informed strategic financial planning. Healthcare Financial Management, 55(11):46-56, 2001.

Belien, J. and Demeulemeester, E. Building cyclic master surgery schedules with leveled resulting bed occupancy. European Journal of Operational Research, 176(2):1185-1204, 2007.

Belien, J. and Demeulemeester, E. A branch-and-price approach for integrating nurse and surgery scheduling. European Journal of Operational Research, 189 (3):652-668, 2008. 
Bellanti, F., Carello, G., Della Croce, F., and Tadei, R. A greedy-based neighborhood search approach to a nurse rostering problem. European Journal of Operational Research, 153(1):28-40, 2004.

Berrada, I., Ferland, J. A., and Michelon, P. A multi-objective approach to nurse scheduling with both hard and soft constraints. Socio-Economic Planning Sciences, 30(3):183-193, 1996.

Bertels, S. and Fahle, T. A hybrid setup for a hybrid scenario: combining heuristics for the home health care problem. Computers $\mathcal{E}$ Operations Research, 33 (10):2866-2890, 2006.

Bester, M. J., Nieuwoudt, I., and Vuuren, J. H. Finding good nurse duty schedules: a case study. Journal of Scheduling, 10(6):387-405, 2007.

Biro, P. and Cechlarova, K. Inapproximability of the kidney exchange problem. Information Processing Letters, 101(5):199-202, 2007.

Blake, J. T., Dexter, F., and Donald, J. Operating room managers use of integer programming for assigning block time to surgical groups: a case study. Anesthesia and Analgesia, 94:143-148, 2002.

Blake, J. T. and Donald, J. Mount Sinai Hospital uses integer programming to allocate operating room time. Interfaces, 32(2):63-73, 2002.

Boldy, D., editor. Operational research applied to health services. St. Martin's Press, New York, 1981.

Bortfeld, T., Chan, T. C. Y., Trofimov, A., and Tsitsiklis, J. N. Robust management of motion uncertainty in intensity-modulated radiation therapy. $O p$ erations Research, 56(6):1461-1473, 2008.

Brailsford, S. and Harper, P.(Guest Eds.) Journal of the Operational Research Society. Special issue on Operational Research in Health. 58(2), 2007.

Brailsford, S. and and Harper, P. (Guest Eds.) European Journal of Operational Research. Feature cluster: OR in Health. 185(3), 2008.

Branas, C. C., MacKenzie, E. J., and ReVelle, C. S. A trauma resource allocation model for ambulances and hospitals. Health Services Research, 35: 489-507, 2000.

Brandeau, M., Sainfort, F., and Pierskalla, W., editors. Operations Research and Health Care. A Handbook of Methods and Applications. Kluwer's International Series, 2004. 
Brandeau, M. L. Allocating resources to control infectious diseases. In Brandeau, M. L., Sainfort, F., and Pierskalla, W. P., editors, Operations Research and Health Care. A Handbook of Methods and Applications., pages 443-464. Kluwer's International Series, 2004.

Brandeau, M. L., Zaric, G. S., and Richter, A. Resource allocation for control of infectious diseases in multiple independent populations: beyond costeffectiveness analysis. Journal of Health Economics, 22(4):575-598, 2003.

Bruni, M., Conforti, D., Sicilia, N., and Trotta, S. A new organ transplantation location-allocation policy: a case study of Italy. Health Care Management Science, 9(2):125-142, 2006.

Burke, E. K., Curtois, T., Post, G., Qu, R., and Veltman, B. A hybrid heuristic ordering and variable neighbourhood search for the nurse rostering problem. European Journal of Operational Research, 188(2):330-341, 2008.

Burke, E. K., Curtois, T., Qu, R., and Vanden Berghe, G. A scatter search methodology for the nurse rostering problem. Journal of the Operational Research Society, (to be published).

Burke, E. K., de Causmaecker, P., Berghe, G. V., and Landeghem, H. V. The state of the art of nurse rostering. Journal of Scheduling, 7(6):1099-1425, 2004.

Burke, E. K., de Causmaecker, P., Petrovic, S., and Vanden Berghe, G. Metaheuristics for handling time interval coverage constraints in nurse scheduling. Applied Artificial Intelligence, 20(9):743-766, 2006.

Cardoen, B., Demeulemeester, E., and Belin, J. Operating room planning and scheduling: A literature review. European Journal of Operational Research, 201(3):921-932, 2010.

Carter, M. W. and Blake, J. T. Using simulation in an acute-care hospital: easier said than done. In Brandeau, M. L., Sainfort, F., and Pierskalla, W. P., editors, Operations Research and Health Care. A Handbook of Methods and Applications, pages 191-215. Kluwer's International Series, 2004.

Carter, M. W., Golden, B. L., and Wasil, E. A. (Guest Eds.), Interfaces. Special issue on Applications of Management Science and Operations Research models and methods to problems in Health Care. 39(3), 2009.

Carter, M. W. and Lapierre, S. D. Scheduling emergency room physicians. Health Care Management Science, 4:347-360, 2001. 
Catlin, A., Cowan, C., Hartman, M., and Heffler, S. National health spending in 2006: A year of change for prescription drugs. Health Affairs, 27(1):14-29, 2008.

Cayirli, T. and Veral, E. Outpatient scheduling in health care: A review of literature. Production \& Operations Management, 12(4), 2003.

Center for Health Care Management. http://www.chcm.ubc.ca/news.cfm/. (last visited on September 9, 2009).

Center for O.R. in Medicine and HealthCare at GeorgiaTech. http://www2. isye.gatech.edu/ evakylee/medicalor/index.htm. (last visited on September $9,2009)$.

Center of excellence in Mathematical Sciences (MITACS). http://www.mitacs. ca. (last visited on September 9, 2009).

Centre for Operational Research and Applied Statistics. http://www.mams. salford.ac.uk/CORAS/Research/Health. (last visited on September 9, 2009).

Centre for Research in Healthcare Engineering. http://crhe.mie.utoronto.ca/. (last visited on September 9, 2009).

Chaovalitwongse, W., Pardalos, P., Iasemidis, L., Shiau, D.-S., and Sackellares, J. Applications of global optimization and dynamical systems to prediction of epileptic seizures. In Pardalos, P., Sackellares, J., Iasemidis, L. and Carney, P., editors, Quantitative Neuroscience: models, algorithms, diagnostics, and therapeutic applications. Kluwer, 2003.

Chaovalitwongse, W. A., Fan, Y.-J., and Sachdeo, R. C. Novel optimization models for abnormal brain activity classification. Operations Research, 56(6): 1450-1460, 2008.

Chaovalitwongse, W. A., Prokopyev, O. A., and Pardalos, P. M. Electroencephalogram (EEG) time series classification: applications in epilepsy. Annals of Operations Research, 148:227-250, 2006.

Cheang, B., Lib, H., Lim, A., and Rodrigues, B. Nurse rostering problems: a bibliographic survey. European Journal of Operational Research, 151:447-460, 2003.

Chick, S. E., Mamani, H., and Simchi-Levi, D. Supply chain coordination and influenza vaccination. Operations Research, 56(6):1493-1506, 2008. 
Chien, C.-F., Tseng, F.-P., and Chen, C.-H. An evolutionary approach to rehabilitation patient scheduling: a case study. European Journal of Operational Research, 189:1234-1253, 2008.

Chu, S. and Chu, L. A modeling framework for hospital location and service allocation. International Transactions in Operational Research, 7:539-568, 2000 .

Cote, M. J., Syam, S. S., Vogel, W. B., and Cowper, D. C. A mixed integer programming model to locate traumatic brain injury treatment units in the department of veterans affairs: a case study. Health Care Management Science, 10:253-267, 2007.

Cote, M. J. and Tucker, S. L. Four methodologies to improve healthcare demand forecasting. Healthcare Financial Management, 55(5):54-58, 2001.

Daskin, M. S. and Dean, L. K. Location of health care facilities. InBrandeau, M. L., Sainfort, F., and Pierskalla, W. P., editors, Operations Research and Health Care. A Handbook of Methods and Applications, pages 43-76. Kluwer's International Series, 2004.

David, I. and Yechiali, U. A time-dependent stopping problem with application to live organ transplants. Operations Research, 33:491-504, 1985.

Davies, R. and Brailsford, S. C. Screening for diabetic retinopathy. In Brandeau, M. L., Sainfort, F., and Pierskalla, W. P., editors, Operations Research and Health Care. A Handbook of Methods and Applications., pages 493-518. Kluwer's International Series, 2004.

Davies, R. and Bensley, D. (Guest eds.). Journal of the Operational Research Society. Special issue on Meeting health challenges with OR. 56(2), 2005.

Department of Health and Human Services, USA. http://www.hhs.gov/. (last visited on September 9, 2009).

Dexter, A. and Traub, R. Which algorithm for scheduling add-on elective cases maximizes operating room utilization? Anesthesiology, 91:1491-1500, 1999.

Doerner, K. F. and Reimann, M. (Guest Eds.). Computers \& Operations Research. Special issue on Logistics of Health Care Management. 34(3), 2007.

Dowsland, K. Nurse scheduling with tabu search and strategic oscillation. European Journal of Operational Research, 106(2-3):393-407, 1998. 
Dowsland, K. and Thompson, J. M. Solving a nurse scheduling problem with knapsacks, networks and tabu search. Journal of the Operational Research Society, 51(2-3):825-833, 2000.

Earnshaw, S. R., Hicks, K., Richter, A., and Honeycutt, A. A linear programming model for allocating HIV prevention funds with state agencies: a pilot study. Health Care Management Science, 10:239-252, 2007.

Earnshaw, S. R., Richter, A., Sorensen, S. W., Hoerger, T. J., Hicks, K. A., Engelgau, M., Thompson, T., Narayan, K. M. V., Williamson, D. E., Gregg, E., and Zhang, P. Optimal allocation of resources across four interventions for type 2 diabetes. Medical Decision Making, 22(5):S80-S91, 2002.

Pilgrim, H. (Guest Ed.) Journal of simulation. Feature cluster: Simulation in Healthcare. 3(3), 2009.

Barjis, J. (Guest Ed.) Simulation. Special issue on Modeling 8 s simulation in healthcare., (forthcoming).

Ozcan, Y. A. (Guest Ed.). Health Care Management Science. Special issue on Contemporary health care applications in OR/MS. 7(4), 2004.

Ehrgott, M., Gler, C., Hamacher, H. W., and Shao, L. Mathematical optimization in intensity modulated radiation therapy. 4OR, 6(3):199-262, 2008.

Eldabi, T., Paul, R. J., and Young, T. Simulation modelling in healthcare: reviewing legacies and investigating futures. Journal of the Operational Research Society, 58(2):262-270, 2007.

Ernst, A. T., Jiang, H., Krishnamoorthy, M., and Sier, D. Staff scheduling and rostering: a review of applications, methods and models. European Journal of Operational Research, 153(1):3-27, 2004.

EURO working group on OR applied to health services. http://www management . soton. ac.uk/ORAHS/index.php. (last visited on September 9, 2009).

EURO Working Group on OR in Computational Biology, Bioinformatics and Medicine. http://euro-cbb.ku.edu.tr/. (last visited on September 9, 2009).

Felici, G. and Gentile, C. A polyhedral approach for the staff rostering problem. Management Science, 50(3):381-393, 2004.

Ferris, M. C., Lim, J., and Shepard, D. M. Optimization tools for radiation treatment planning in Matlab. In Brandeau, M. L., Sainfort, F., and Pierskalla, W. P., editors, Operations Research and Health Care. A Handbook 
of Methods and Applications., pages 775-806. Kluwer's International Series, 2004.

Ferris, M. C., Lim, J. H., and Shepard, D. M. Radiosurgery treatment planning via nonlinear programming. Annals of Operations Research, 119(1-4):247$260,2003$.

Finarelli Jr, H. J. and Johnson, T. Effective demand forecasting in 9 steps. Healthcare Finance Manage, 58(11):52-58, 2004.

Flessa, S. Priorities and allocation of health care resources in developing countries: a case-study from the Mtwara region, Tanzania. European Journal of Operational Research, 150(1):67-80, 2003.

Floudas, C. A. and Pardalos, P. M., editors. Encyclopedia of Optimization. Springer, 2009.

Fone, D., Hollinghurst, S., Temple, M., Round, A., Lester, N., Weightman, A., Roberts, K., Coyle, E., Bevan, G., and Palmer, S. Systematic review of the use and value of computer simulation modelling in population health and healthcare delivery. Journal of Public Health Medicine, 25:325-335, 2003.

Fox, C., Lynch, B., Aleman, D., Li, H., Romeijn, H., and Dempsey, J. A scientific comparison of inverse treatment plan quality using a convex nonlinear programming model as a function of beam quality and beam number. Medical Physics, 33(6):2192-2192, 2006.

Glover, F. and Laguna, M. Tabu Search. In Pardalos, P. and Resende, M., editors, Handbook of Applied Optimization. Oxford University Press, 2002.

Goddard, J. and Tavakoli, M. Efficiency and welfare implications of managed public sector hospital waiting lists. European Journal of Operational Research, 184(2):778-792, 2008.

Grano, M. L. D., Medeiros, D. J., and Eitel, D. Accommodating individual preferences in nurse scheduling via auctions and optimization. Health Care Management Science, 2008.

Green, L. V. Capacity planning and management in hospitals. In Brandeau, M. L., Sainfort, F., and Pierskalla, W. P., editors, Operations Research and Health Care. A Handbook of Methods and Applications, pages 15-41. Kluwer's International Series, 2004. 
Green, L. V. and Savin, S. Reducing delays for medical appointments: A queueing approach. Operations Research, 56(6):1526-1538, 2008.

Guinet, A. and Chaabane, S. Operating theatre planning. International Journal of Production Economics, 85(1):69-81, 2003.

Gunal, M. and Pidd, M. Understanding target-driven action in emergency department performance using simulation. Emergency Medicine Journal, 26: 724-727, 2009.

Gunal, M. and Pidd, M. Discrete event simulation for performance modelling in healthcare: A review of the literature. Journal of Simulation, forthcoming.

Gupta, D. and Denton, B. Appointment scheduling in health care: Challenges and opportunities. IIE Transactions, 40:800-819, 2008.

Gutjahr, W. J. and Rauner, M. S. An ACO algorithm for a dynamic regional nurse-scheduling problem in Austria. Computers 83 Operations Research, 34 (3):642-666, 2007.

Haijema, R., van der Wal, J., and van Dijk, N. M. Blood platelet production: optimization by dynamic programming and simulation. Computers $\mathscr{E}$ Operations Research, 34(3):760-779, 2007.

Hall, R. W., editor. Patient flow: Reducing delay in healthcare delivery., volume 91 of International Series in Operations Research $\&$ Management Science. Springer, 2006.

Hall, S. N., Jacobson, S. H., and Sewell, E. C. An analysis of pediatric vaccine formulary selection problems. Operations Research, 56(6):1348-1365, 2008.

Hans, E., Wullink, G., van Houdenhoven, M., and Kazemier, G. Robust surgery loading. European Journal of Operational Research, 185(3):1038-1050, 2008.

Harper, P. R., Sayyad, M. G., de Senna, V., Shahani, A. K., Yajnik, C. S., and Shelgikar, K. M. A systems modelling approach for the prevention and treatment of diabetic retinopathy. European Journal of Operational Research, 150(1):81-91, 2003.

Harper, P. R. and Shahani, A. K. Modelling for the planning and management of bed capacities in hospitals. Journal of the Operational Research Society, 53:11-18, 2002. 
Harper, P. R. and Shahani, A. K. A decision support system for the care of HIV and AIDS patients in India. European Journal Of Operational Research, 147(1):187-197, 2003.

Harper, P. R., Shahani, A. K., Gallagher, J. E., and Bowie, C. Planning health services with explicit geographical considerations: a stochastic locationallocation approach. Omega, 33(2):141-152, 2005.

Harris, Z. K. Efficient allocation of resources to prevent HIV infection among injection drug users: the Prevention Point Philadelphia (PPP) needle exchange program. Health Economics, 15(2):147-158, 2006.

Health and Social Services. The OR Society of UK. http://www.theorsociety. com/orshop/ (ehuf12y1exdztu55zcrdmg3x)/orcontent.aspx?inc=health.htm. (last visited on September 9, 2009).

Health Management Consortium. http://www.mmr.mcgill.ca/centers_Health. html. (last visited on September 9, 2009).

Health Policy Institute. http://www.bu.edu/mvp/about/institute.html. (last visited on September 9, 2009).

Health Systems Research Center. http://www.lums.lancs.ac.uk/departments/ ManSci/Research/ResGroups/hsrc/. (last visited on January 18, 2010).

Henderson, S. G. and Mason, A. J. Ambulance service planning: simulation and data visualisation. In Brandeau, M. L., Sainfort, F., and Pierskalla, W. P., editors, Operations Research and Health Care. A Handbook of Methods and Applications., pages 77-102. Kluwer's International Series, 2004.

Hodgson, M. J., Laporte, G., and Semet, F. A covering tour model for planning mobile health care facilities in Suhum District, Ghana. Journal of Regional Science, 38(4):621-638, 1998.

Holder, A. Radiotherapy treatment design and linear programming. In Brandeau, M. L., Sainfort, F., and Pierskalla, W. P., editors, Operations Research and Health Care. A Handbook of Methods and Applications., pages 741-774. Kluwer's International Series, 2004.

Holder, A. and Salter, B. Radiation oncology and optimization. In Greenberg, H. J., editor, Tutorials on Emerging Methodologies and Applications in Operations Research. Springer, NY, 2005. 
Hornberger, J. C. and Ahn, J. H. Deciding eligibility for transplantation when a donor kidney becomes available. Medical Decision Making, 17(3):160-170, 1997.

Ikegami, A. and Niwa, A. A subproblem-centric model and approach to the nurse rostering problem. Mathematical Programming, 97(3):517-541, 2003.

INFORMS Health Applications Section. http://ramanujan.math.trinity.edu/ HealthApp/index.shtml. (last visited on September 9, 2009).

Ingolfsson, A., Budge, S., and Erkut, E. Optimal ambulance location with random delays and travel times. Health Care Management Science, 11:262274,2008 .

Jacobson, S. H., Karnani, T., and Sewell, E. C. Analyzing the economic value of the hepatitis B-Haemophilus influenzae type B combination vaccine by reverse engineering a formulary selection algorithm. Vaccine, 21(17-18):2169-2177, 2003.

Jacobson, S. H., Karnani, T., and Sewell, E. C. Assessing the impact of wastage on pediatric vaccine immunization formulary costs using a vaccine selection algorithm. Vaccine, 22(17-18):2307-2315, 2004.

Jacobson, S. H. and Sewell, E. C. Using Monte Carlo simulation to determine combination vaccine price distributions for childhood diseases. Health Care Management Science, 5(2):135-145, 2002.

Jacobson, S. H., Sewell, E. C., Deuson, R., and Weniger, B. An integer programming model for vaccine procurement and delivery for childhood immunization: a pilot study. Health Care Management Science, 2(1):1-9, 1999.

Jacobson, S. H., Sewell, E. C., Proano, R. A., and Jokela, J. A. Stockpile levels for pediatric vaccines: how much is enough? Vaccine, 24(17):3530-3537, 2006 .

Jiang, L. and Giachetti, R. E. A queueing network model to analyze the impact of parallelization of care on patient cycle time. Health Care Management Science, 11:248-261, 2008.

Jones, S. S., Thomas, A., Evans, R. S., Welch, S. J., Haug, P. J., and Snow, G. L. Forecasting daily patient volumes in the emergency department. Academic Emergency Medicine, 15(2):159-170, 2008. 
Joosten, T., Bongers, I., and Janssen, R. Application of lean thinking to health care: issues and observations. International Journal for Quality in Health Care, 21(5):341-347, 2009.

Jun, J., Jacobson, S., and Swisher, J. Applications of discrete-event simulation in health care clinics: A survey. Journal of the Operational Research Society, 50(2), 1999.

Kaandorp, G. C. and Koole, G. Optimal outpatient appointment scheduling. Health Care Management Science, 10:217-229, 2007.

Kahn, J. G., Brandeau, M. L., and Dunn-Mortimer, J. OR modeling and AIDS policy: From theory to practice. Interfaces, 28:3-22, 1998.

Kaplan, E. H. and Brandeau, M. L. (editors). Modeling the AIDS epidemic: planning, policy, and prediction. Raven Press, New York, NY, 1994.

Kaplan, E. H. and Brookmeyer, R. (editors). Quantitative Evaluation of HIV Prevention Programs. Yale University Press, 2002.

Kaplan, E. H. and Wein, L. M. Decision making for bioterror preparedness: examples from smallpox vaccination policy. In Brandeau, M. L., Sainfort, F., and Pierskalla, W. P., editors, Operations Research and Health Care. A Handbook of Methods and Applications, pages 519-536. Kluwer's International Series, 2004.

Kokangul, A. A combination of deterministic and stochastic approaches to optimize bed capacity in a hospital unit. Computer Methods and Programs in Biomedicine, 90(1):56-65, 2008.

Kongnakorn, T. and Sainfort, F. Modeling health outcomes for economic analysis. In Brandeau, M. L., Sainfort, F., and Pierskalla, W. P., editors, Operations Research and Health Care. A Handbook of Methods and Applications, pages 255-274. Kluwer's International Series, 2004.

Kopach, R., Balcioglu, B., and Carter, M. Tutorial on constructing a red blood cell inventory management system with two demand rates. European Journal of Operational Research, 185(3):1051-1059, 2008.

Lamiri, M., Xie, X., Dolgui, A., and Grimaud, F. A stochastic model for operating room planning with elective and emergency demand for surgery. European Journal of Operational Research, 185(3):1026-1037, 2008. 
Lapierre, S. D. and Ruiz, A. B. Scheduling logistic activities to improve hospital supply systems. Computers \& Operations Research, 34(3):624-641, 2007.

Lee, C. P., Chertow, G. M., and Zenios, S. A. Optimal initiation and management of dialysis therapy. Operations Research, 56(6):1428-1449, 2008.

Lee, E. K. and Sofer, A. (Guest Eds.) Annals of Operations Research. Special issue on Operations Research in medicine-computing and optimization in medicine and life sciences. 148(1), 2006.

Lee, E. K. and Wu, T.-L. Disease diagnosis: Optimization-based methods. In Floudas, C. A. and Pardalos, P. M., editors, Encyclopedia of Optimization, pages 753-784. Springer, 2009.

Lee, E. K. and Zaider, M. Optimization and decision support in brachytherapy treatment planning. In Brandeau, M. L., Sainfort, F., and Pierskalla, W. P., editors, Operations Research and Health Care. A Handbook of Methods and Applications, pages 721-740. Kluwer's International Series, 2004.

Liberatore, M. J. and Nydick, R. L. The analytic hierarchy process in medical and health care decision making: a literature review. European Journal of Operational Research, 189(1):194-207, 2008.

Lim, G. J. and Lee, E. K. (editors). Optimization in Medicine and Biology. Taylor and Francis, Auerbach Publications, 2007.

Little, J. and Coughlan, B. Optimal inventory policy within hospital space constraints. Health Care Management Science, 11:177-183, 2008.

Litvak, N., van Rijsbergen, M., Boucherie, R. J., and van Houdenhoven, M. Managing the overflow of intensive care patients. European Journal of Operational Research, 185(3):998-1010, 2008.

Lovejoy, W. S. and Li, Y. Hospital Operating Room Capacity Expansion. Management Science, 48(11):1369-1387, 2002.

Maillart, L. M., Ivy, J. S., Ransom, S., and Diehl, K. Assessing dynamic breast cancer screening policies. Operations Research, 56(6):1411-1427, 2008.

Marianov, V. and Taborga, P. Optimal location of public health centres which provide free and paid services. Journal of the Operational Research Society, 52:391-400, 2001. 
Mark, J., Temple, F., and Fone, D. Implementing national guidance on prevention of coronary heart disease: clinical governance and computer simulation modelling. British Journal of Clinical Governance, 1:27-33, 2002.

Mayhew, L. and Smith, D. Using queuing theory to analyze the governments 4-h completion time target in accident and emergency departments. Health Care Management Science, 11:11-21, 2008.

Medical Operations Research Laboratory (morLAB). http://morlab.mie. utoronto.ca/. (last visited on September 9, 2009).

Molema, J. J. W., Groothuis, S., Baars, I. J., Kleinschiphorst, M., Leers, E. G. E., Hasman, A., and van Merode, G. G. Healthcare system design and part-time working doctors. Health Care Management Science, 10:365-371, 2007.

Moz, M. and Pato, M. V. A bi-objective network flow approach for nurse rerostering. In Gouveia, L. and Mouro, C., editors, Proceedings of the INOC 2005-International Network Optimization Conference, Lisbon, March 2005.

Mullinax, C. and Lawley, M. Assigning patients to nurses in neonatal intensive care. Journal of the Operational Research Society, 53:25-35, 2002.

Murawski, L. and Church, R. L. Improving accessibility to rural health services : the maximal covering network improvement problem. Socio-Economic Planning Sciences, 43(2):102-110, 2009.

Myers, C. and Green, T. Forecasting demand and capacity requirements. Healthcare Financial Management, 58(8):34-37, 2004.

Nahmias, S. Perishable inventory theory: A review. Operational Research, 30: 680-780, 1982 .

Naseer, A., Eldabi, T., and Jahangirian, M. Cross-sector analysis of simulation methods: a survey of defense and healthcare. Transforming Government: People, Process and Policy, 3(2):181-189, 2009.

National Institute of Health, USA. http://www.nih.gov/. (last visited on September 9, 2009).

Ndiaye, M. and Alfares, H. Modeling health care facility location for moving population groups. Computers $\&$ Operations Research, 35(7):2154-2161, 2008. 
Nigmatulina, K. R. and Larson, R. C. Living with influenza: impacts of government imposed and voluntarily selected interventions. European Journal of Operational Research, 195(3):613-627, 2009.

Office of Disease Prevention and Health Promotion, USA. http://odphp. osophs . dhhs.gov/. (last visited on September 9, 2009).

Ogulata, S. N., Koyuncu, M., and Karakas, E. Personnel and patient scheduling in the high demanded hospital services: A case study in the physiotherapy service. Journal of Medical Systems, 32:221-228, 2008.

Oliveira, M. and Bevan, G. Modelling the redistribution of hospital supply to achive equity taking account of patient's behaviour. Health Care Management Science, 9:19-30, 2006.

Oliveira, M. D. and Bevan, G. Modelling hospital costs to produce evidence for policies that promote equity and efficiency. European Journal of Operational Research, 185(3):933-947, 2008.

Operations Research for Improved Cancer Care. http://www.orincancercare. org/cihrteam/index.html/. (last visited on September 9, 2009).

Operations Research Manhattan. http://www.orie.cornell.edu/orie/ manhattan/index.cfm\#PHL. (last visited on September 9, 2009).

Ozkarahan, I. Allocation of surgeries to operating rooms by goal programing. Journal of Medical Systems, 24(6):339-378, 2000.

Paltiel, A. D., Kuntz, K. M., Weiss, S. T., and Fuhlbrigge, A. L. An asthma policy model. In Brandeau, M. L., Sainfort, F., and Pierskalla, W. P., editors, Operations Research and Health Care. A Handbook of Methods and Applications., volume 70 of International Series in Operations Research 83 Management Science, pages 659-693. Kluwer's International Series, 2004.

Papageorgiou, J. C. Some operations research applications to problems of health care systems (a survey). International Journal Biomedical Computation, 9(2): 101-14, 1978.

Pardalos, P., Sackellares, J., Carney, P., and Iasemidis, L., editors. Quantitative Neuroscience: Models, Algorithms, Diagnostics, and Therapeutic Applications, volume 2 of Biocomputing. Springer, 2004.

Pato, M. V. and Moz, M. Solving a bi-objective nurse rerostering problem by using a utopic pareto genetic heuristic. Journal of Heuristics, 14(4):359-374, 2008. 
Patrick, J. and Puterman, M. L. Improving resource utilization for diagnostic services through flexible inpatient scheduling: A method for improving resource utilization. Journal of the Operational Research Society, 58:235-245, 2007.

Patrick, J., Puterman, M. L., and Queyranne, M. Dynamic multipriority patient scheduling for a diagnostic resource. Operations Research, 56(6):1507-1525, 2008.

Persson, M. and Persson, J. A. Health economic modeling to support surgery management at a Swedish hospital. Omega, 37:853-863, 2009.

Pham, D.-N. and Klinkert, A. Surgical case scheduling as a generalized job shop scheduling problem. European Journal of Operational Research, 185(3): 1011-1025, 2008.

Pierskalla, W. and Brailer, D. Applications of operations research in health care delivery. Handbooks in $O R$ \& $M S, 6: 468-505,1994$.

Pierskalla, W. and Rath, G. Nurse scheduling using mathematical programming. Operations Research, 24(5):857-870, 1976.

Pierskalla, W. P. Supply chain management of blood banks. In Brandeau, M. L., Sainfort, F., and Pierskalla, W. P., editors, Operations Research and Health Care. A Handbook of Methods and Applications, pages 103-145. Kluwer's International Series, 2004.

Prastacos, G. Blood inventory management: An overview of theory and practice. Management Science, 30:777-800, 1984.

Preciado-Walters, F., Langer, M., Rardin, R., and Thai, V. Column generation for IMRT cancer therapy optimization with implementable segments. Annals of Operations Research, 148(1):65-79, 2006.

Puente, J., Gomez, A., Fernandez, I., and Priore, P. Medical doctor rostering problem in a hospital emergency department by means of genetic algorithms. Computers \& Industrial Engineering, 56(4), 2009.

Punnakitikashem, P., Rosenberger, J. M., and Behan, D. B. Stochastic programming for nurse assignment. Computational Optimization and Applications, 40 (3):321-349, 2008.

Rahman, S. and Smith, D. K. Deployment of rural health facilities in a developing country. Journal of the Operational Research Society, 50(9):892-902, 1999. 
Rahman, S. and Smith, D. K. Use of location-allocation models in health service development planning in developing nations. European Journal of Operational Research, 123:437-452, 2000.

Rauner, M. and Vissers, J.M.H.(Guest Eds.). European Journal of Operational Research. Special issue on O.R. applied to health services: Planning for the future with scarce resources. 150(1), 2003.

Rauner, M. S. and Bajmoczy, N. How many AEDs in which region? An economic decision model for the Austrian Red Cross. European Journal of Operational Research, 150(1):3-18, 2003.

Rauner, M. S., Kraus, M., and Schwarz, S. Competition under different reimbursement systems: the concept of an internet-based hospital management game. European Journal of Operational Research, 185(3):948-963, 2008.

Regenstrief Center for Healthcare Engineering. http://www.purdue.edu/dp/ rche/. (last visited on September 9, 2009).

Richter, A. Duct tape for decision makers: the use of OR models in pharmacoeconomics. In Brandeau, M. L., Sainfort, F., and Pierskalla, W. P., editors, Operations Research and Health Care. A Handbook of Methods and Applications, pages 275-296. Kluwer's International Series, 2004.

Ridge, J. C., Jones, S. K., Nielsen, M. S., and Shahani, A. K. Capacity planning for intensive care units. European Journal of Operational Research, 105(2): 346-355, 1998.

Romeijn, E. and Zenios, S. (Guest Eds.). Operations Research. Special issue on Operations Research in Health Care. 56(6), 2008.

Roth, A. E., Sonmez, T., and Unver, M. U. Kidney exchange. Quarterly Journal of Economics, 119(2):457-488, 2004.

Royston, G. One hundred years of operational research in Health - UK 19482048. Quarterly Journal of Economics, 60(1):169-179, 2009.

Ruiz, M. S., Gable, A. R., Kaplan, E. H., Stoto, M. A., Fineberg, H. V., and Trussell, J., (editors), No Time To Lose: Getting More from HIV Prevention. National Academy Press, Washington, DC, 2001.

Sanders, G. D., Bayoumi, A. M., Sundaram, V., Bilir, S. P., Neukermans, C. P., Rydzak, C. E., Douglass, L. R., Lazzeroni, L. C., Holodniy, M., and Owens, D. K. Cost-effectiveness of screening for HIV in the era of highly active 
antiretroviral therapy. New England Journal Of Medicine, 352(6):570-585, 2005.

Sandiki, B., Maillart, L. M., Schaefer, A. J., Alagoz, O., and Roberts, M. S. Estimating the patients price of privacy in liver transplantation. Operations Research, 56(6):1393-1410, 2008.

Santibanez, P., Begen, M., and Atkins, D. Surgical block scheduling in a system of hospitals: an application to resource and wait list management in a british columbia health authority. Health Care Management Science, 10(3):269-282, 2007.

Segev, D. L., Gentry, S. E., Warren, D. S., Reeb, B., and Montgomery, R. A. Kidney paired donation and optimizing the use of live donor organs. JAMA - The Journal of the American Medical Association, 293:1883-1890, 2005a.

Segev, D. L., Gentry, S. E., Warren, D. S., Reeb, B., and Montgomery, R. A. Optimized match. http://www.optimizedmatch.com, 2005b. (last visited on September 9, 2009).

Sewell, E. C. and Jacobson, S. H. Using an integer programming model to determine the price of combination vaccines for childhood immunization. Annals of Operations Research, 119:261-1284, 2003.

Shechter, S. M., Bryce, C. L., Alagoz, O., Kreke, J. E., Stahl, J. E., Schaefer, A. J., Angus, D. C., and Roberts, M. S. A clinically based discrete-event simulation of end-stage liver disease and the organ allocation process. Medical Decision Making, 25(2):199-209, 2005.

Sherali, H. D. Equivalent weights for lexicographic multi-objective programs: Characterizations and computations. European Journal of Operational Research, 11(4):367-379, 1982.

Sherali, H. D., Ramahi, M. H., and Saifee, Q. J. Hospital resident scheduling problem. Production Planning and Control, 13(2):220-233, 2002.

Shmueli, A., Sprung, C. L., and Kaplan, E. H. Optimizing admissions to an intensive care unit. Health Care Management Science, 6(3):131-136, 2003.

Shu, H., Yan, Y., Bao, X., Fu, Y., and Luo, L. Treatment planning optimization by quasi-Newton and simulated annealing methods for gamma unit treatment system. Physics in Medicine \& Biology, 43:2795-2805, 1998. 
Shuman, L. J., Speas, R. D., and Young, J. P., editors. Operations research in health care: a critical analysis. The Johns Hopkins University Press, London, 1975 .

Siebert, U., Sroczynski, G., Marckmann, G., and Hillemanns, P. Costeffectiveness of human papillomavirus testing in cervical cancer screening. a review of decision analyses. Gynakologe, 36(4):341-348, 2003.

Singer, M. E. and Younossi, Z. M. Cost effectiveness of screening for hepatitis $\mathrm{C}$ virus in asymptomatic, average-risk adults. American Journal of Medicine, 111(8):614-621, 2001.

Smith, H. K., Harper, P. R., Potts, C. N., and Thyle, A. Planning sustainable community health schemes in rural areas of developing countries. European Journal of Operational Research, 193(3):768-777, 2009.

Smith-Daniels, V. L., Schweikhart, S. B., and Smith-Daniels, D. E. Capacity management in health care services: Review and future directions. Decision Sciences, 19:889-919, 1988a.

Smith-Daniels, V. L., Scweikhart, S. B., and Smith-Daniels, D. E. Capacity management in health care services: Review and future research directions. Decision Sciences, 19:889-919, 1988b.

Sofer, A., Zeng, J., and Mun, S. K. Optimal biopsy protocols for prostate cancer. Annals of Operations Research, 119:63-74, 2003.

Stahl, J. E., Kong, N., Shechter, S. M., Schaefer, A. J., and Roberts, M. S. A methodological framework for optimally reorganizing liver transplant regions. Medical Decision Making, 25(1), 2005.

Steeg, J. and Schroder, M. A hybrid approach to solve the periodic home health care problem. In Kalcsics, J. and Nickel, S., editors, Operations Research, Proceedings 200\%, Selected Papers of the Annual International Conference of the German Operations Research Society (GOR), Saarbrücken, September 57, 200\%, pages 297-302. Springer, 2007.

Stein, K., Dalziel, K., Walker, A., Jenkins, B., Round, A., and Royle, P. Screening for hepatitis $\mathrm{C}$ in injecting drug users: a cost utility analysis. Journal of Public Health, 26(1):61-71, 2004.

Steuer, R. E. Multiple Criteria Optimization: Theory, Computation and Application. John Wiley \& Sons, New York, NY, 1985. 
Stummer, C., Doerner, K., Focke, A., and Heidenberger, K. Determining location and size of medical departments in a hospital network: a multiobjective decision support approach. Health Care Management Science, 7:63-71, 2004.

$\mathrm{Su}, \mathrm{X}$. and Zenios, S. A. Patient choice in kidney allocation: A sequential stochastic assignment model. Operions Research, 53(3):443-455, 2005.

$\mathrm{Su}, \mathrm{X}$. and Zenios, S. A. Recipient choice can address the efficiency-equity trade-off in kidney transplantation: A mechanism design model. Management Science, 52(11):1647-1660, 2006.

Sundaramoorthi, D., Chen, V. C. P., Rosenberger, J. M., Kim, S. B., and Buckley-Behan, D. F. A data-integrated simulation model to evaluate nursepatient assignments. Health Care Management Science, 2008.

Swaminathan, J. M. Decision support for allocating scarce drugs. Interfaces, 33(2):1-11, 2003.

Taranto, S. E., Harper, A. M., Edwards, E. B., Rosendale, J. D., McBride, M. A., Daily, O. P., Murphy, D., Poos, B., Reust, J. S., and Schmeiser, B. W. Developing a national allocation model for cadaveric kidneys. In Winter Simulation Conference, pages 1971-1977, 2000.

Topaloglu, S. A multi-objective programming model for scheduling emergency medicine residents. Computers $\mathcal{E}$ Industrial Engineering, 51(3):375-388, 2006.

Umble, M. and Umble, E. J. Utilizing buffer management to improve performance in a healthcare environment. European Journal of Operational Research, 174(2):1060-1075, 2006.

Valouxis, C. and Housos, E. Hybrid optimization techniques for the work-shift and rest assignment of nursing personnel. Artificial Intelligence in Medicine, $20(2): 155-175,2000$.

van Berkel, P. T. and Blake, J. T. A comprehensive simulation for wait time reduction and capacity planning applied in general surgery. Health Care Management Science, 10:373-385, 2007.

van de Klundert, J., Muls, P., and Schadd, M. Optimizing sterilization logistics in hospitals. Health Care Management Science, 11:23-33, 2008.

van den Hout, W. B., Smits, J. M. A., Deng, M. C., Hummel, M., Schoendube, F., Scheld, H. H., Persijn, G. G., and Laufer, G. The heart-allocation simulation model: a tool for comparison of transplantation allocation policies. Transplantation, 76(10):1492-1497, 2003. 
van Genugten, M. L. L., Heijnen, M.-L. A., and Jager, J. C. Pandemic influenza and healthcare demand in the Netherlands: Scenario analysis. Emerging Infectious Diseases, 9(5), 2003.

Verter, V. and Lapierre, S. D. Location of preventive health care facilities. Annals of Operations Research, 110(1-4):123-132, 2003.

Wake, G. M. G. H., Boland, N., and Jennings, L. S. Mixed integer programming approaches to exact minimization of total treatment time in cancer radiotherapy using multileaf collimators. Computers 83 Operations Research, 36(3):795-810, 2009.

Wang, C.-W., Sun, L.-M., Jin, M.-H., Fu, C.-J., Liu, L., Chan, C.-H., and Kao, C.-Y. A genetic algorithm for resident physician scheduling problem. In GECCO '0\%: Proceedings of the 9th annual conference on genetic and evolutionary computation, pages 2203-2210, New York, NY, USA, 2007. ACM.

Warner, M., Keller, B., and Martel, S. Automated nurse scheduling. Journal Social Health System, 2(2):66-80, 1990.

Webb, S. Optimization by simulated annealing of three-dimensional conformal treatment planning for radiation fields defined by a multileaf collimator. Physics in Medicine and Biology, 36:1201-1226, 1991.

Wu, J. T., Wein, L. M., and Perelson, A. S. Optimization of influenza vaccine selection. Operations Research, 53(3):456-476, 2005.

Wu, X. G., Zhu, Y. P., and Luo, L. M. Linear programming based on neural networks for radiotherapy treatment planning. Physics in Medicine and Biology, 45:719-728, 2000.

Xue, J. L., Ma, J. Z., Louis, T. A., and Collins, A. J. Forecast of the number of patients with end-stage renal disease in the United States to the year 2010. Journal of the American Society Nephrology, 12:2753-2758, 2001.

Young, T., Brailsford, S., Connell, C., Davies, R., Harper, P., and Klein, J. H. Using industrial processes to improve patient care. British Medical Journal, 328:162-164, 2004.

Zaric, G. S. and Brandeau, M. L. Optimal investment in a portfolio of HIV prevention programs. Medical Decision Making, 21(5):391-408, 2001.

Zaric, G. S. and Brandeau, M. L. Dynamic resource allocation for epidemic control in multiple populations. Ima Journal Of Mathematics Applied In Medicine And Biology, 19(4):235-255, 2002. 
Zenios, S. A. Optimal control of a paired-kidney exchange program. Management Science, 48(3):328-342, 2002.

Zenios, S. A. Models for kidney allocation. In Brandeau, M. L., Sainfort, F., and Pierskalla, W. P., editors, Operations Research and Health Care. A Handbook of Methods and Applications, pages 537-554. Kluwer's International Series, 2004.

Zenios, S. A., Chertow, G. M., and Wein, L. M. Dynamic allocation of kidneys to candidates on the transplant waiting list. Operations Research, 48(4):549569,2000 .

Zhang, B., Murali, P., and Belson, D. A mixed integer programming approach for allocating operating room capacity. Journal of the Operational Research Society, 60(5):663-673, 2009a.

Zhang, Y., Berman, O., and Verter, V. Incorporating congestion in preventive healthcare facility network design. European Journal of Operational Research, 198(3):922 - 935, 2009b. 